\title{
Parametric study to analyze the performance of a solar greenhouse dryer for the drying of Olive Mill Wastewater
}

\author{
BOURAOUI CHAIMA, \\ Ionized and Reactive Media Studies Research Unit, \\ Preparatory Institute of Engineering Studies of Monastir, \\ Ibn Eljazzar Street, 5019 \\ TUNISIA \\ BEN NEJMA FAYÇAL, \\ Ionized and Reactive Media Studies Research Unit, \\ Preparatory Institute of Engineering Studies of Monastir, \\ Ibn Eljazzar Street, 5019 \\ TUNISIA
}

\begin{abstract}
The objective of this paper is to improve the design of an even-span greenhouse by analyzing the effect of some climatic and design parameters on its performance of drying Olive Mill wastewater. A mathematical model describing the coupled heat and mass transfers inside the dryer was developed and simulated under different condition using COMSOL Multiphysics. An analysis of the dryer performance was conducted in terms of the obtained overall drying efficiency. The findings indicated that the use of a shallow and large pond dyer under hot climatic conditions can improve significantly the drying process. The dryer high and the extension added to the configuration had not achieved any enhancement to the drying efficiency, but can affect the calculations time and installation cost. The developed model was thus used as an effective tool to optimize the drying process.
\end{abstract}

KeyWords: even-span greenhouse, Olive Mill Wastewater, COMSOL Multiphysics, overall drying efficiency, optimize.

Received: December 27, 2020. Revised: January 15, 2021. Accepted: February 3, 2021. Published: February 24, 2021.

\section{Introduction}

$\mathrm{T}$ HE olive oil extraction process yields large quantities of a hazardous waste known as Olive Mill Wastewater (OMWW). Despite its fertilizing value, this effluent can affect negatively the aquatic and terrestrial ecosystems once disposed without pretreatment [1].

Many studies have been conducted to find a cost effective technique for its management [2], [3]. The high moisture of this waste makes the solar greenhouse drying an economic and environmentally friendly technique to produce a sludge that can be used in industrial [4] and agricultural [5] application or even as a fuel [6].

In the recent years, the use of solar greenhouse drying has increased significantly for different purposes as an alternative to expensive and pollutant fossil fuels [7], [8]. Therefore, it is essential to predict the performance of the solar drying system in order to adequately meet the needs of the consumers and to obtain an optimized design. The basic parameters of the dryer such as dimensions and climatic conditions should be investigated. However, experimental researches are often limited by their high cost and technical difficulties. Developing a simulation model seems to be a key tool to predict and analyze the drying system.

Several research papers have been conducted on the study of the effect of different parameters on a solar greenhouse dryer. Bekkioui et al. [9] examined the effect of the wood thickness and density, the climatic conditions, the air velocity and the ventilation mode on the performance of a solar greenhouse dryer with glazed walls. Jaradat et al. [10] develoed a model based on the mass balance approach to identify the optimum design parameters of a solar still used to the management of OMWW. The effect of the depth and area of the still on its performance were discussed. Abur et al. [11] used the MATLAB language to develop a model which allows to study the influence of the gazing number, the wind speed, the thermal conductivity of the insulating material, the collector tilt and the initial moisture content of the crop on the collector area and efficiency.

The aim of this study is to assess the influence of some climatic and geometrical parameters that can influence the performance of a modified even span solar greenhouse dryer. The different configuration were compared in terms of the overall drying efficiency. 


\section{The Dryer Configuration}

\subsection{The geometry}

In the present paper, the considered solar greenhouse dryer is a modified even span one. The computational domain was first created as a two dimensional model. As it presents a symmetrical nature, this domain is limited to the half of the dryer which contributed to minimize the computing time (Fig.1). In order to analyze the effect of the studied parameters, different configurations were simulated.

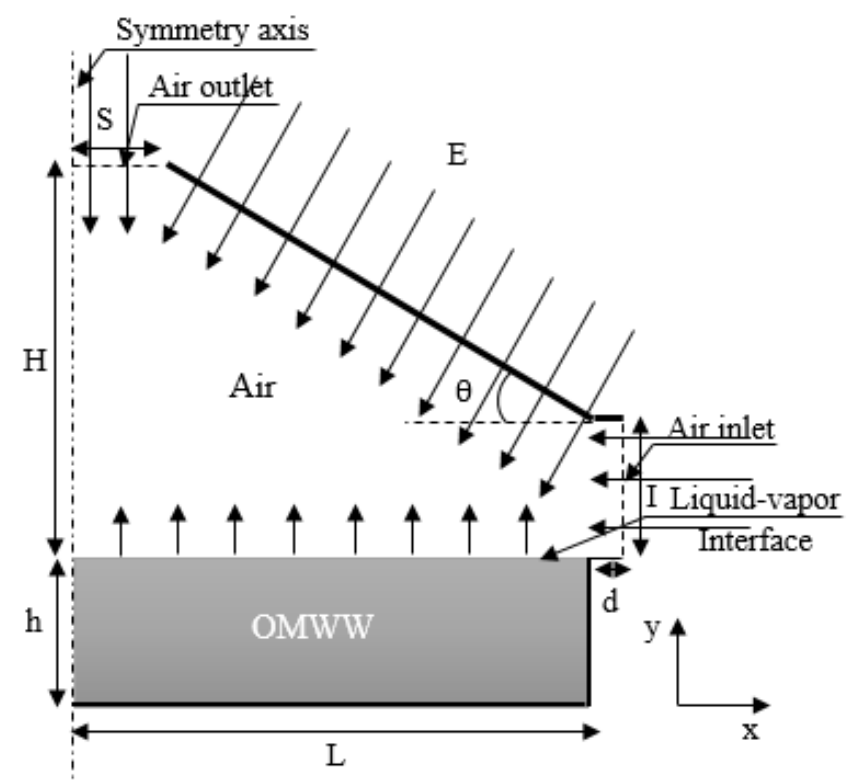

Fig. 1 the configuration of the dryer

A. The mesh grid

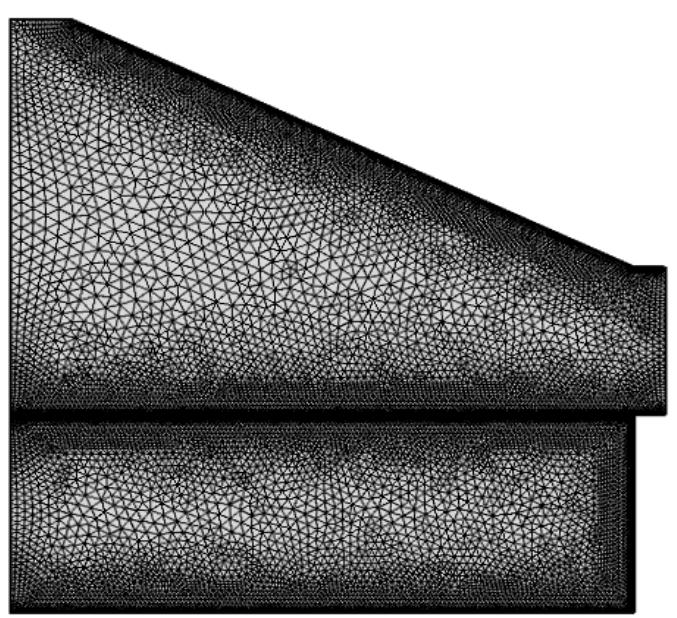

Fig. 2 the proposed mesh

Then, the computational domain was meshed using an unstructured triangular mesh grid with a refinement near the airliquid interface. Fig.2 presents the proposed mesh chosen after a grid independence test.

\section{The Mathematical Model}

A mathematical model was developed to solve the conservation equations that describe the coupled heat and mass transfers occurring during our drying problem. The simplifying assumptions as well as the resulted equation system for the air and the OMWW have already been formulated elsewhere [12]. The considered initial and boundary conditions have been also reported.

\section{The Method}

The resolution of the retained equations system was carried out by means of the finite element method of COMSOL Mutiphysics software.

A time dependent first step of ten minute was executed to initiate the calculation and control the flow and the coupled heat and mass transfers by utilizing a fully coupled approach. The simulation of model for the rest of the drying period was performed in a second time dependent step where the segregated approach was used.

For these two steps, the Backward differentiation formula method was selected for the time stepping.

The different studied cases, where the dryer dimensions are varied, are discussed in terms of the predicted overall drying efficiency evolution during a typical day considered for the month of July with an average ambient temperature of $304 \mathrm{~K}$ and an hourly solar radiation as depicted in Fig. In fact, this parameter seems to be a great indicator on the dryer performance as it evaluate how efficiently the capacity of the heated air by solar radiation to absorb moisture. It is expressed as:

$$
\eta_{o}(t)=\frac{\int_{0}^{t} \int_{A} L_{v} \dot{m} d A d t}{\int_{0}^{t} E A d t}
$$

Where $\dot{m}, \mathrm{~L}_{\mathrm{v}}, \mathrm{A}, \mathrm{E}$ are respectively the evaporated mass $(\mathrm{kg})$, the latent heat of vaporization of the water $(\mathrm{kJ} / \mathrm{kg})$, the interface area and the solar radiation flux density $\left(\mathrm{W} / \mathrm{m}^{2}\right)$.

\section{Results and Discussions}

To acquire a reliable predictive character, we established a radiative and convective validation. The same procedure used to validate a horizontal greenhouse dryer, studied in a previous paper [12], was applied for the studied geometry by considering a tilt angle $\theta=0^{\circ}$.

\subsection{The effect of the climatic conditions}

To evaluate the effect of the climatic conditions mainly the solar radiation flux and the average temperature of the ambient air for the Sfax (Tunisia) region, the simulation has been performed on typical days of the year which consisted on the solstices of winter (22 December) and summer (21 June) as well as the equinoxes of autumn (23 September) and spring (20 March). The hourly solar radiation flux and the average ambient 
temperature during these days are presented respectively in Fig. 3 and Fig.4.

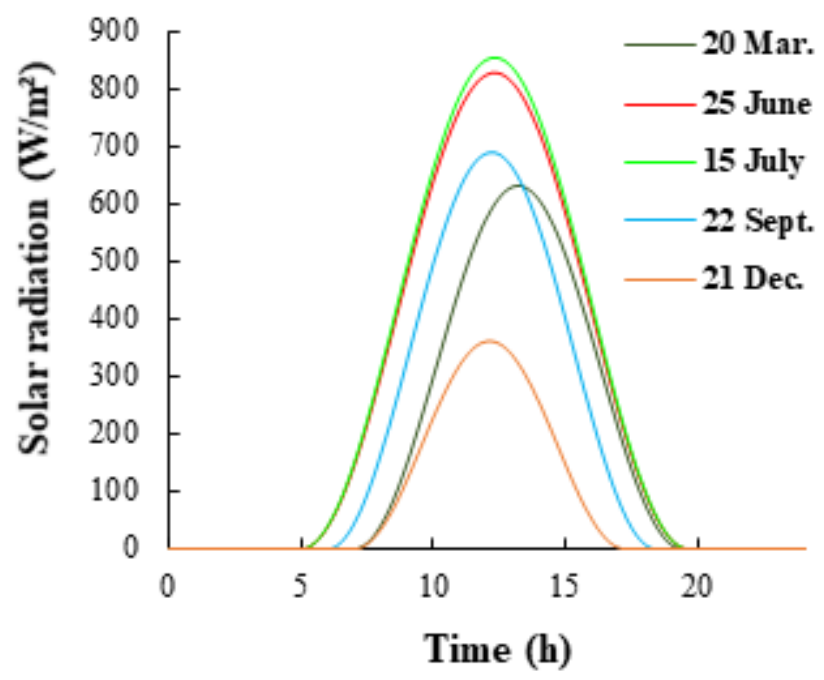

Fig. 3 the evolution of the hourly solar radiation flux during the proposed days

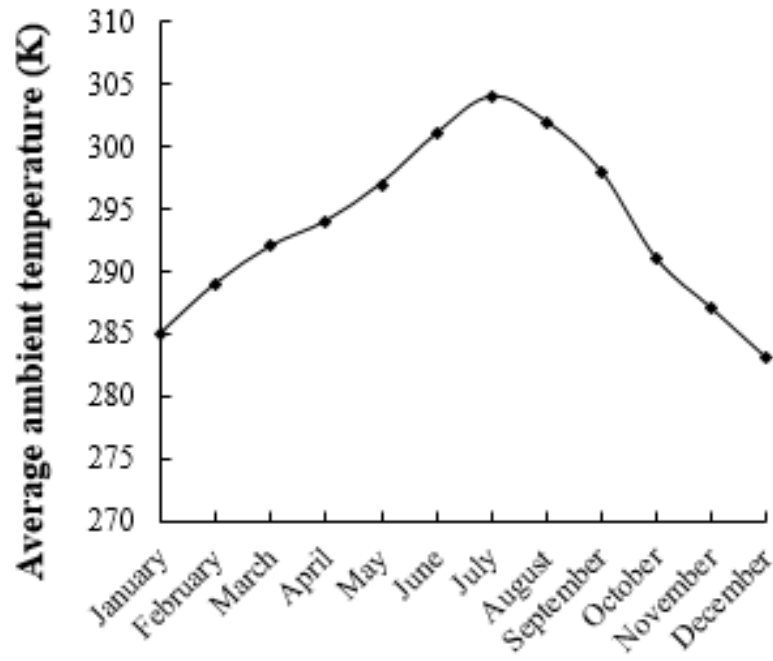

Fig. 4 the evolution of the monthly average ambient temperature during the day

Fig. 5 shows that the drying process during the day of June which presented the summer is the most efficient reaching $37.3 \%$ at the end of the proposed day contrary to that during the day of December which reached only $14.1 \%$ at the end of this day. In fact, important solar radiation flux with a long sunshine period and a high air temperature are supplied to the dryer which contribute to the warm up of the OMWW and the increase of the kinetic energy of its molecules which will then have sufficient energy escape from the surface. Therefore, solar drying during a hot season can increase significantly its efficiency.

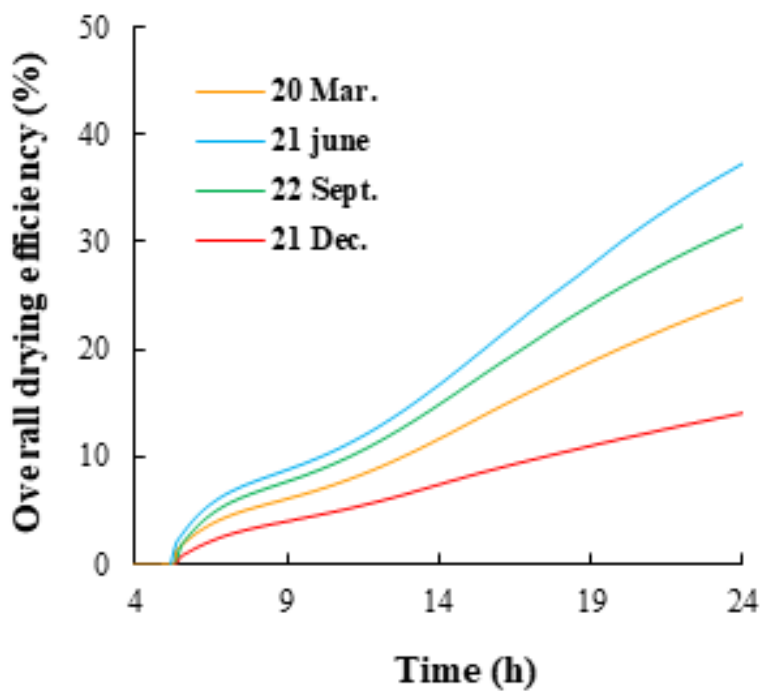

Fig. 5 the effect of the weather conditions $(\mathrm{h}=0.2 \mathrm{~m}, \mathrm{I}=0.15 \mathrm{~m}$, $\mathrm{H}=0.4, \mathrm{~d}=0.03 \mathrm{~m}, \mathrm{~L}=0.6 \mathrm{~m}, \mathrm{~S}=0.06$ )

\subsection{The effect of the dryer pond depth}

The drying of OMWW depends not only on the climatic conditions but also on the dimensions of the proposed greenhouse dryer. The dryer pond depth is one of the important parameters that can influence on the drying process.

Fig.6 illustrates the significant difference between the drying efficiency using different depths of the dryer pond. It can be seen that the smallest tested depth $(\mathrm{h}=0.1 \mathrm{~m})$ provides the most important efficiency which reached $61.6 \%$ compared to $40.7 \%$, $30.8 \%$ and $25.3 \%$ respectively for $\mathrm{h}=0.2 \mathrm{~m}, \mathrm{~h}=0.3 \mathrm{~m}$ and $\mathrm{h}=0.4 \mathrm{~m}$. This can be explained by the fact that a shallow pond is more sensitive to heat which make OMWW temperature higher while a deep one exhibit a clearly different evaporative response due to its thermal inertia. Such findings confirmed well the results obtained by Jaradat et al [10].

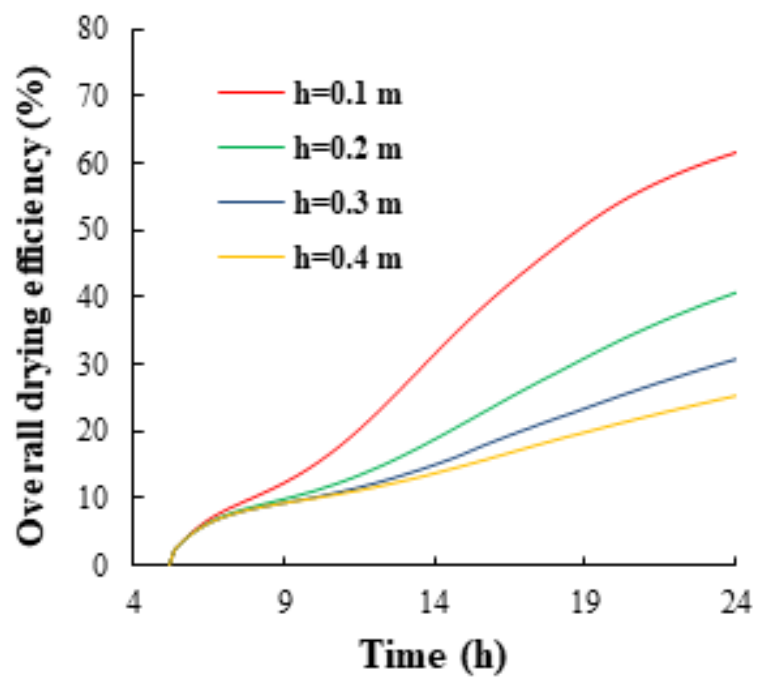

Fig. 6 the effect of the dryer pond depth $(I=0.15 \mathrm{~m}, \mathrm{H}=0.4, \mathrm{~d}=0.03$ $\mathrm{m}, \mathrm{L}=0.6 \mathrm{~m}, \mathrm{~S}=0.06$ ) 


\subsection{The effect of the dryer height}

The model predicted also the overall drying efficiency evolution for five configurations with five different height as presented in Fig.7. Based on these profiles, it can be noted that varying the height of the dryer has not achieved any improvement in the drying efficiency. A low height can thus be used for the design of the dryer as it can reduce the construction cost. However, the dryer height should not be very low to not affect the air flow circulation.

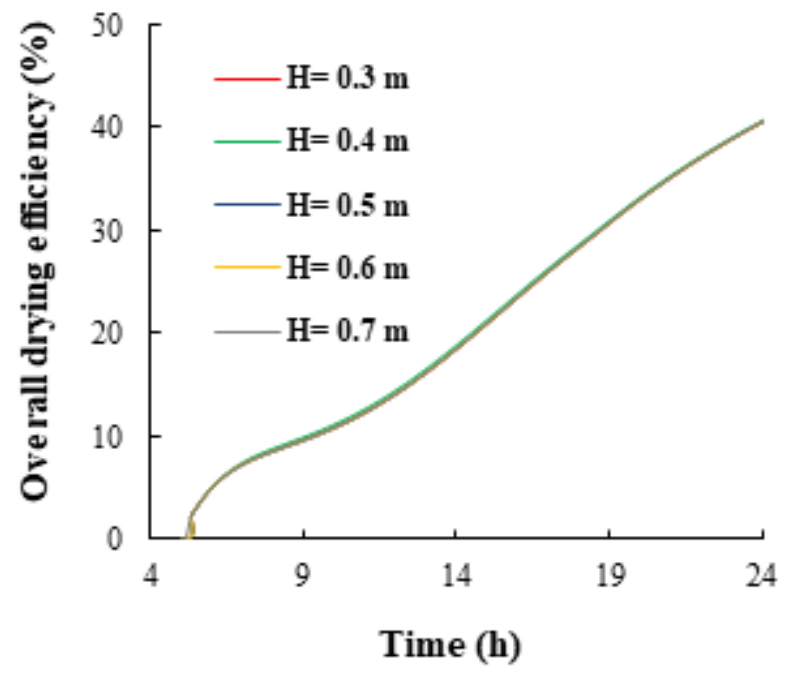

Fig. 7 the effect of the dryer height $(\mathrm{h}=0.2 \mathrm{~m}, \mathrm{I}=0.15 \mathrm{~m}, \mathrm{~d}=0.03 \mathrm{~m}$, $\mathrm{L}=0.6 \mathrm{~m}, \mathrm{~S}=0.06$ )

A. The effect of the dryer pond extend

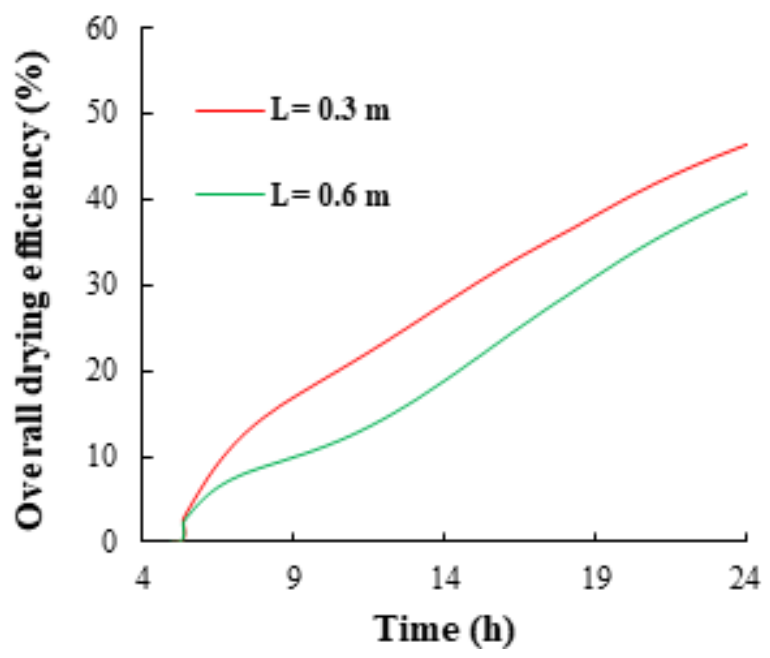

Fig. 8 the effect of the dryer pond the extend $(\mathrm{h}=0.2 \mathrm{~m}, \mathrm{I}=0.15 \mathrm{~m}$, $\mathrm{H}=0.4, \mathrm{~d}=0.03 \mathrm{~m}, \mathrm{~S}=0.06$ )

The OMWW surface extend can also plays a key role in the evaporation process. The evolution of the overall drying efficiency of two dryers with two different widths is presented in Fig.8. It is obvious that larger OMWW surface provides a more efficient drying process. Actually, at the end of the day, a configuration with a width $\mathrm{L}=0.6 \mathrm{~m}$ reached an overall drying efficiency of $46.4 \%$ compared to $40.7 \%$ for a configuration with a width $\mathrm{L}=0.3 \mathrm{~m}$. Therefore, larger pond can increase the exchange surface between the liquid to be dried and the hot air inside the dryer, which permits more water molecules to escape and improve the evaporation process.

\subsection{The effect of the extension}

In the simulated configurations, an extension was added to the dryer design which provide faster calculation. Therefore, studying its effect on the drying performance in an important issue.

Fig. 9 depicts the evolution of the overall drying efficiency for different $d$ values. As indicated from this figure, the $d$ extension has not any influence on the drying efficiency. Choosing the $\mathrm{d}$ value depends thus only on the calculation time and the raw material cost.

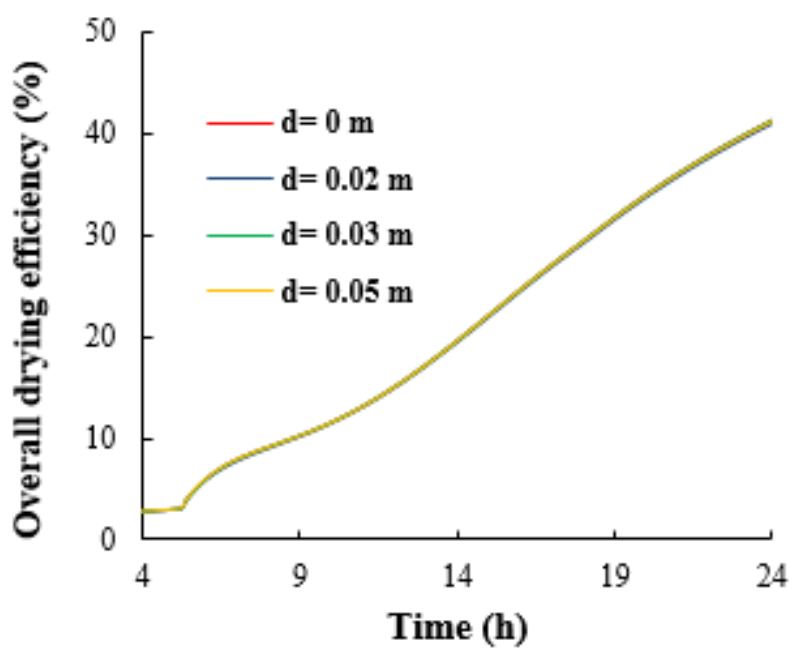

Fig. 9 the effect of the extension $(\mathrm{h}=0.2 \mathrm{~m}, \mathrm{I}=0.15 \mathrm{~m}, \mathrm{H}=0.4, \mathrm{~S}=0.06$, $\mathrm{L}=0.6 \mathrm{~m})$

\section{Conclusion}

The performance of an even-span greenhouse was numerically evaluated using a parametric study where the influence of some climatic and geometric parameters is discussed. Important overall drying efficiency was obtained for a shallow and large pond dryer taken under hot climatic conditions. In contract, the dryer height and the extension $\mathrm{d}$ had not affect the drying efficiency.

The used model showed its reliability to help designers in choosing optimal parameters which suggest its use to study the effect of more other parameters. Therefore, after an in-depth parametric study, the proposed dryer can be employed effectively on a large scale to treat OMWW. 


\section{References}

[1] B. Peikert, G. E. Schaumann, D. Bibus, J. Fischer, U. Braun, and J. Brunkhardt, "Effects of olive oil mill wastewater on chemical, microbiological, and physical properties of soil incubated under four different climatic conditions," Biol Fertil Soils, vol. 53, no. 1, pp. 89-102, Jan. 2017.

[2] P. Paraskeva and E. Diamadopoulos, "Technologies for olive mill wastewater (OMW) treatment: a review," Journal of Chemical Technology \& Biotechnology, vol. 81, no. 9, pp. 1475-1485, 2006.

[3] E. Aboutaleb, G. Kamel, and M. Hellal, "Investigation of Effective Treatment Techniques for Olive Mill Wastewater," Egyptian Journal of Chemistry, vol. 61, no. 3, pp. 415-422, Jun. 2018.

[4] N. Hytiris, I. E. Kapellakis, R. L. R. de, and K. P. Tsagarakis, "The potential use of olive mill sludge in solidification process," Resources, Conservation and Recycling, vol. 40, no. 2, pp. 129-139, Jan. 2004.

[5] H. Rigane, M. Chtourou, I. Ben Mahmoud, K. Medhioub, and E. Ammar, "Polyphenolic compounds progress during olive mill wastewater sludge and poultry manure cocomposting, and humic substances building (Southeastern Tunisia)," Waste Manag Res, vol. 33, no. 1, pp. 73-80, Jan. 2015.

[6] F. A. Agblevor, H. Abdellaoui, K. Halouani, and S. H. Beis, "Pyrolytic Conversion of Olive Mill Wastewater Sludge to Biofuels Using Red Mud as Catalyst," International Journal of Energy and Power Engineering, vol. 6, no. 6, Art. no. 6, Dec. 2017.

[7] O. Prakash and A. Kumar, "Solar greenhouse drying: A review," Renewable and Sustainable Energy Reviews, vol. 29, pp. 905-910, Jan. 2014.

[8] P. Singh, V. Shrivastava, and A. Kumar, "Recent developments in greenhouse solar drying: A review," Renewable and Sustainable Energy Reviews, vol. 82, pp. 3250-3262, Feb. 2018.

[9] N. Bekkioui, A. Zoulalian, A. Hakam, and H. EZZahraouy, "Using a parametric study to analyse the performance of wood solar dryers with glazed walls," Maderas. Ciencia y tecnología, vol. 19, no. 4, pp. 463-470, Oct. 2017.

[10]A. Jaradat, S. Gharaibeh, A. Khalid, and R. Hatamleh, "Optimum Design Parameters of Solar Still Unit Operating toward Olive Mill Wastewater Management," Jordan Journal of Civil Engineering, vol. 13, no. 1, pp. 51-60, Sep. 2018.

[11]B. Ternenge, H. Dandakouta, A. Adisa, and R. Ejilah, "Parametric study for Solar Dryer Design," vol. 55, no. 284, pp. 430-440, Aug. 2019.

[12]C. Bouraoui and F. Ben Nejma, "Numerical study of the greenhouse solar drying of olive mill wastewater under different conditions," Advances in Mechanical Engineering, vol. 12, no. 4, p. 1687814019889748 , Apr. 2020.

\section{Creative Commons Attribution License 4.0 (Attribution 4.0 International, CC BY 4.0)}

This article is published under the terms of the Creative Commons Attribution License 4.0 https://creativecommons.org/licenses/by/4.0/deed.en US 